\title{
Closing the Gap: Flexible and Dynamic Design Education to Better Prepare Digital Media Design Students for Professional Practice
}

\author{
Katja Fleischmann, James Cook University, Queensland, Australia
}

\begin{abstract}
The dynamic and fast changing nature of digital media presents many challenges for design professionals as well as for design educators. Managing the increasing complexity of technology is one of them. Surprisingly, the digital media design industry's switch to multidisciplinary collaborative teamwork as a response to the increasing complexity of technology has been rarely anticipated by higher digital media design education perhaps because subject 'silos' make collaboration more difficult. Major research into the employability of graduates from design disciplines in the United Kingdom (UK) and Australia revealed that employers are concerned about the preparedness of undergraduate digital media design students when entering the profession. The research highlighted the lack of professional skills and soft skills such as verbal communication of ideas and teamwork. Clearly it is time to respond to the widening gap between professional practice and design education. Currently under development and testing at an Australian university is a new learning and teaching model, referred to as the POOL Model. This new model is a multidisciplinary system of interdependent collaboration and expertise exchange across university, industry and community sectors. The Pool Model is based on existing resources and implemented as an integral part of the curriculum at undergraduate level in order to prepare students for collaborative multidisciplinary practice and meaningful careers in industry. This paper describes the development and implementation of an alternative learning and teaching model. The rational for the development of the model is described and its evaluation through the application of accepted research principles and methodologies.
\end{abstract}

Keywords: Digital Media Design Education, Learning and Teaching Model, Learning and Teaching Pool, Multidisciplinary Collaboration, Design Education

\section{Introduction}

TN THE CREATIVE industries today, many multimedia design projects are highly complex requiring designers to work in multidisciplinary teams (Bley 2004, Sommese 2007, Whyte \& Bessant 2007). These collaborative multidisciplinary environments are rarely reflected in digital media design education (Design Skills Advisory Panel 2007, Kelly 2005, Szenasy 2004, Triggs 2004).

Digial media design education engages students in subjects such as multimedia and website design, animation, motion graphic design, interaction and information design. The design and development of projects in these areas is often associated with the extensive use of software and information technology (IT). The increasing complexity of technology and the resulting "magnitude of many design problems require specialized expertise residing in many individuals.... In complex collaborations, design is a robust social activity that demands new kinds of relationships and organizational structures" (Staples 2001, p.9).

Design Principles and Practices: An International Journal

Volume 5, Number 4, 2011, http://www.Design-Journal.com, ISSN 1833-1874 
The lack of opportunities allowing students to engage in multidisciplinary learning situations reflective of industry practice has become critical as recent studies show that tertiary digital media design education fails to equip students with the skills and attributes needed by employers. Teamworking and communication skills especially are named as areas in need of improvement (Design Skill Advisory Panel 2007, Ball 2003). Furthermore, there is a clearly identified need for stronger links to the creative industries in order to better prepare students for the demands of the market (Ball 2003, Design Council 2005, Design Skills Advisory Panel 2007).

The challenge is to provide a learning and teaching model that is aligned with current industry practice and equips digital media design students with discipline-specific and industryrelevant knowledge, technical and interpersonal skills along with a strong understanding of the industry and communities. As their future work environment will require them to work in collaborative multidisciplinary teams, undergraduate digital media design students therefore not only need to learn their discipline individually but must also learn how to collaborate with other disciplines, especially with disciplines beyond the creative arts.

\section{Objectives}

This paper describes the development and implementation of an alternative learning and teaching model, the POOL Model, for undergraduate digital media design education as an integral part of the curriculum that allows students to develop discipline specific skills while engaging in multidisciplinary teamwork with disciplines beyond the creative arts. The rational for the development of the model is briefly described and can be found in more depth elsewhere (Fleischmann 2008a, Fleischmann 2008b, Fleischmann 2010). The focus of this paper however, is on the implementation of the POOL Model across creative arts disciplines and beyond in a $3^{\text {rd }}$ year level subject and its evaluation through the application of accepted research principles and methodologies producing data that allow evidence-based decisions for further development of the approach.

\section{Collaboration across Disciplines in Design Education}

The value of collaborative multidisciplinary learning and teaching approaches in tertiary design education is recognised worldwide (Business Week 2007, Design Council 2007, Design Skills Advisory Panel 2007). Students engaged in such an environment are able to develop interactive attributes such as communication and teamworking skills, and personal attributes such as willingness to learn, flexibility, commercial awareness and problemsolving (Harvey, Locke \& Morey 2002). Next to discipline-specific skills development, employers in the creative industries consider such attributes to be extremely valuable in succeeding in today's global market (Ball 2003).

It is evident that the need to implement multidisciplinary collaboration in educational environments is becoming more widely recognized: for example new models such as schools of design thinking (d.schools) have been established (Rotman School in Toronto, the d.school at Stanford and Potsdam, and the Institute of Design in Chicago) offering interdisciplinary graduate programs (West 2007) which focus on innovation based on multidisciplinary collaboration. 
While earlier collaborative innovations in design education had often special event character (e.g. Omnium Project; Only Connect - international collaboration project), more recently institutions started developing educational concepts that base their undergraduate curriculum around multidisciplinary collaboration within or even beyond the creative arts.

Two examples are the Bachelor of International Game Architecture and Design at NHTV (the Netherlands) and the Bachelor of MultiMediaArt at the University of Applied Sciences in Salzburg (Austria). In both programs theory and practice of multidisciplinary collaboration is presented as an integral part of the study program. The practical component (the project work) is based on emulating the industry model, for example at NHTV game design and game developer students work together on projects in the GameLab throughout their degree.

\section{Strengthening Links between Education and Industry}

External input into the academic environment becomes critical as the multimedia industry is developing at such a high speed that digital media design education can easily become outdated if not meaningfully connected to the industry. "Linking academic endeavour and the world are critical for students, the university and for the community in these times of change where connectedness and experience are valued overtly alongside discipline specific skills" (Collins et al. 2007, p.103). The need for stronger links between industry and design education as a key to being able to offer up-to date content and provide students with insight into the real-world working environment was also identified by the Design Skill Advisory Panel (2007) which conducted extensive research among design industry professionals in the UK in 2005 and 2006. As a result, they recommended building a network of visiting design professionals who could provide input into the relevant design education programs (The Design Skills Advisory Panel 2007, p.42).

\section{Strengthening Links between Education and Community}

"Building bridges with local communities has become, and clearly will continue to be, an essential platform of every university's mission statement" (Snell 2006, p. 2). In general, digital media design education provides opportunities to connect with the local community due to its nature of "being a creative discipline and a servant of clients" (Price 2005, p.1). Community engagement opportunities and the development of relationships with small or medium sized enterprises (SMEs) are commonly created through community organizations or SMEs seeking support from their local university due to a lack of resources to finance professional design solutions. These client-service relationships are typically mutually beneficial as students gain valuable experience through being engaged in a real-world project and developing a commercial understanding as well as social responsibility, while the industry or community partner benefits by accessing expertise pro bono.

\section{An Alternative Learning and Teaching Model for Undergraduate Digital Media Design Education: The POOL Model}

Based on an extensive literature review and research conducted with Australian stakeholders such as digital media design professionals, universities, digital media design and information 
technology students (Fleischmann 2010), an alternative learning and teaching model was developed: the POOL Model.

The POOL Model is a multidisciplinary system of interdependent collaborations based on the exchange of expertise across the university, industry and community sectors. At its core, the POOL Model provides a framework in which creative arts students are introduced to multidisciplinary collaborative learning with disciplines beyond the creative arts (e.g. IT, journalism), while at the same time industry and community partners are encouraged to be an integral part of the undergraduate learning environment.

The POOL Model consists of a learning pool and a teaching pool with specialists - students, teaching academics, industry and community partners - from diverse but related disciplines. In each pool, multidisciplinary groups work together to either define a problem and guide the problem-solving process (teaching pool), or to solve a problem (learning pool). Teams formed from both pools include members with expertise fundamental to solving the proposed problem or to guiding the problem-solving process (Fleischmann 2009, Fleischmann 2010).

\section{Research Methods}

The POOL Model was implemented and trialled in three subjects in the Bachelor of New Media Arts offered at the School of Creative Arts at James Cook University in 2009. The most advanced version of the implementation in the Bachelor of New Media Arts and the Bachelor of Information Technology, at the third year level (final semester), is documented in this paper.

Preliminary trials (Fleischmann 2009) introducing multidisciplinary collaborative practice between digital media design and information technology students have informed this study. The overall research study is driven by the overarching research question: What strategies can be put in place to better prepare Digital Media Design students in higher education for the contemporary creative industries?

After ethics approval was obtained, a mixed method approach was applied. Combining elements of quantitative and qualitative research was considered most appropriate to investigate how this multidisciplinary collaboration differs from discipline-based learning and teaching. Benefits and challenges of the POOL Model were, and still are, being investigated by means of the following methods:

The expectations and experience of students was documented through

- An online questionnaire at the beginning, in the middle and the end of the subject. In addition, group interviews were conducted with student teams at the end of the semester to gain a deeper insight and understanding of their experience.

The expectations and experience of teaching academics was documented through

- An online questionnaire at the beginning of the subject. Face-to-Face interviews have been conducted and are still in the process of being completed.

The experience and reflections of industry professionals and community partners was documented through 
- Either face-to-face or telephone interviews around the end of the semester.

Data presented in this paper are from all stages of the online questionnaires given to the digital media design students and teaching academics. In addition feedback obtained from industry partners is presented.

\section{The POOL Model in Action}

The most advanced version of the Pool Model was implemented in 2009 in a subject called Creative Exchange, a third year subject in the Bachelor of New Media Arts at the School of Creative Arts. Formalised collaborations between the School of Creative Arts and other schools (e.g. School of Business, discipline IT) created the base for the learning and teaching pool to include a variety of disciplines. Hence, thirty-three digital media design students and students majoring in digital imaging, digital sound, digital visual arts and performance, along with twenty-two IT students have all been part of the learning pool. The teaching pool contained academics associated with these disciplines with a wide range of expertise in interactive media design, graphic design, photography and photomedia, visual arts and illustration, film production, music, digital sound, theatre, art theory, leadership and various fields of IT. In addition community partners, a regional gallery and dance company, as clients and industry experts from the digital media design and film industry were part of the pool.

During a thirteen-week semester students experienced the planning and production of a large-scale project. From the learning pool, thirteen student teams, with members from at least three different disciplines, were formed. Engaging in a collaborative multidisciplinary team-based learning environment students have devised projects that intersect with new media, technology and the wider community. Examples of projects range from the production of a documentary film that tells the story of a dancer affected by multiple sclerosis to a multiplayer game that utilizes a self-programmed physics engine, computer-enhanced illustrations and sound to create an engaging online experience. Figure 1 shows the team formation from the learning and teaching pool for these two project examples. In total seven of the thirteen teams had either the community or creative industry professionals directly involved in their projects. 


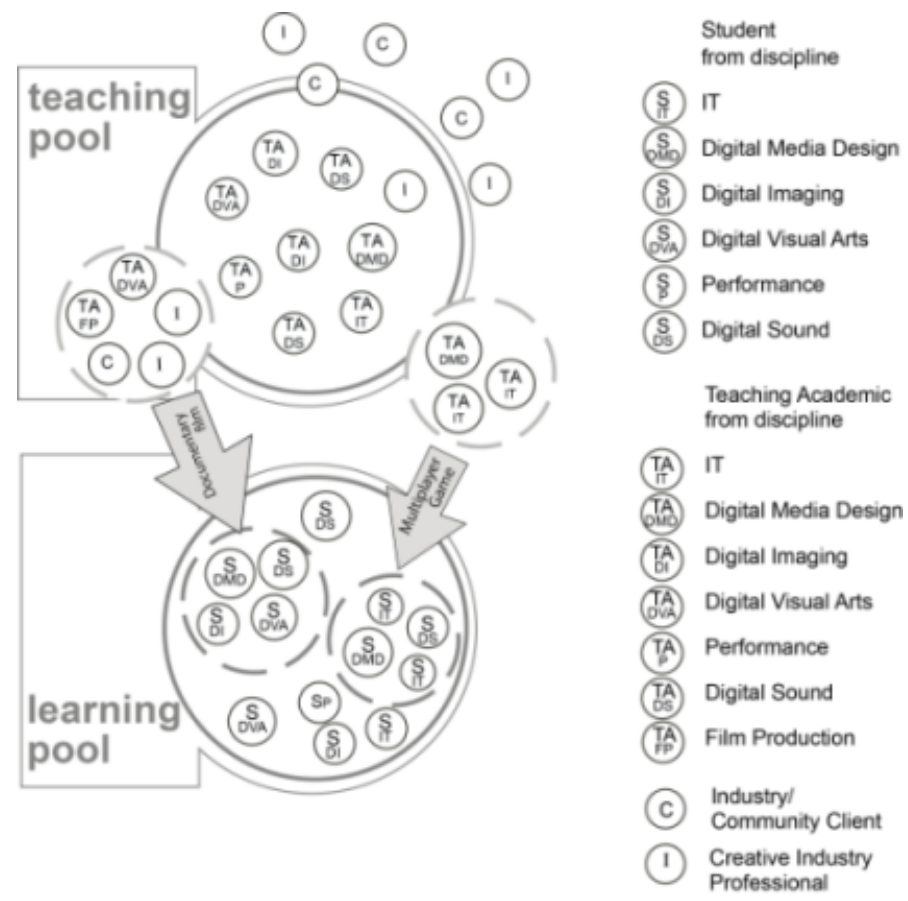

Figure 1: Functioning of the POOL Model; Team Forming for Two Projects

Separately to expertise input and guidance for the project production by academics, industry and community partners, student teams were mentored by a team advisor. The role of the team advisor (teaching academic) was created to monitor all teams, advising them on collaborative and project management practices. Hence dysfunctional teams can be identified and guided in order to resolve their problems. The team advisor also monitors the development of a reflective process journal which documents the project development process and team experiences.

In order to link students' project development to workplace realities all teams pitched their concept to an external panel of teaching academics and in presenting a project prototype to an industry panel consisting of four industry professionals from Germany, Melbourne and the region during the Creative Industry Day when students sought real-world feedback on their projects. The four creative industry professionals were the founder of a dynamic company specialising in the creative industries with a focus on film, music and arts related events; a film scholar, filmmaker and author; the founder of a graphic design company which engages in corporate design work for print media; and the CEO of a small web design business that specialises in combining business needs with technology and design to create user-friendly professional websites suitable for all budgets. The Creative Industry Day included also a panel discussion 'Collaboration and Creative Exchange: Challenges and opportunities for the contemporary artist'.

All thirteen teams presented their final projects in a School of Creative Arts event to peers, academics and people from the industry and community. 


\section{Results}

The participating students and teaching academics were invited to provide feedback on their learning and teaching experienced through earlier outlined methods. The data presented in this paper represents the feedback provided by digital media design students and teaching academics collected through the online questionnaires.

In week 1, thirty-three students, thirteen of whom were digital media design students, participated in the online questionnaire. In week 13, forty-four students, of whom twenty were digital media design students, participated in the online questionnaire.

Of the eleven teaching academics involved in the subject, seven gave feedback through the online questionnaire.

All industry professionals (four) involved in the Creative Industry Day provided feedback via face-to-face or telephone interviews.

\section{Multidisciplinary Collaboration beyond the Creative Arts}

As part of the evaluation process it was important to document the expectations students had before their participation in subject and their experience at the completion of the subject. At the beginning all thirteen digital media design students who participated in the questionnaire in week $1(100 \%)$ and who were part of one of the eight teams thought that their project would benefit from working with students from different disciplines. In week 13 the nineteen digital media design students $(100 \%)$ who answered the question of whether their project had benefited from the working in multidisciplinary teams, stated that their project had indeed benefited. Two reasons were repeatedly given in the qualitative section of the questionnaire:

Firstly, the advantage of having different skill sets on the team, allowing students to complete larger and more complex projects of higher quality, was identified. Sample comments made were: "Working with a team with different strengths and disciplines enables the project to come together. Without this, certain elements of the project that one team member lacks in skill can be picked up by another member" and "The Creative Team would not have achieved such a functional and professional product without the guidance of IT programming, whilst IT would not have achieved such a marketable and appealing product without the conscientious work of the Creative Team".

The second reason given was the recognition that the multidisciplinary teamwork allowed students to concentrate on their own discipline: "everyone had their own specialty which contributed well to the group". Indeed, eighteen digital media design students (90\%) felt that they could concentrate on their area of expertise while being part of the team and only two felt they could not.

Engaging students in multidisciplinary learning environments allows them to gain an insight in, and understanding of, disciplines other than their own. Effective teamwork can only happen when such understanding can be developed for all contributing disciplines and when, as a result, communication is enhanced and more effective. When asked to reflect on the issue, eighteen of the twenty digital media design students who answered (90\%), stated that they got an insight into areas other than their own. Furthermore, eighteen students (95\%), only nineteen answered this question) also developed a better understanding about how people from different disciplines work on projects. 
Overall, from nineteen digital media design students, eleven (58\%) liked working in multidisciplinary teams, $5(26 \%)$ thought it was challenging at times but liked it, and $3(16 \%)$ did not like it but could see the benefits. It was rewarding to see that none of the students selected the option that they would have done better on their own.

From the teaching academics involved in the subject seven provided feedback in the online questionnaire in week 6 . All seven (100\%) agreed that engaging students in multidisciplinary collaboration during their course of study is beneficial for them and will enhance their employability. Furthermore, all seven (100\%) also predicted that the students' projects would benefit through working in multidisciplinary teams.

All participating teaching academics also saw challenges arising for students, when engaging in multidisciplinary work. These were classified by one teaching academic as "typical team work issues" such as "students taking on projects that are too large, weak team members, interpersonal issues, and some supervisors being hard to get time with".

\section{Couching Multidisciplinary Collaboration}

During preliminary trials of the POOL Model in 2009 involving digital media design and IT students (Fleischmann 2009) it became apparent that managing multidisciplinary teams and their issues became often more important than the expertise input during feedback sessions. Instead of providing expertise input and consultation on the project development process, feedback sessions often turned into team counselling sessions which were necessary to help the teams to carry on with their work as a functional team. In some cases disciplinespecific input was not as intense as that needed in order to guide students in their learning and towards a high quality product.

As a result, each team was required to assign a team leader for the Creative Exchange projects and the researcher also introduced a team advisor (a teaching academic with experience in leadership and team management) who coaches the teams and helps them handle their issues on a team management level.

While the team advisor and the two subject coordinators felt that the introduction of the team advisor was extremely helpful in coaching the teams, and left other teaching academics with more time to actually advise on content and guide the discipline-specific learning process; the students' views on the role of the team advisor were mixed.

Of the twenty digital media design students who answered the question regarding the role of the team advisor, ten (50\%) thought it was a good idea, eight (40\%) did not like it and two $(10 \%)$ were not sure. Qualitative feedback varied, for example from showing that the role of team advisor was well understood and experienced as positive: "[The team advisor] was valuable to the mediation we required as a team in order to work through underlying issues at the end of the semester" and "He assisted in issues, bonding and team management, which was beneficial for dysfunctional groups."

One student may have given an indication of why the role of the team advisor was understood in varied ways: "I think that there were too many classes on working as a team and writing about working as a team, rather than teams being able to work on their projects. I feel it is good to touch on these elements, however by year $3 \mathrm{I}$ feel that we have worked on enough group projects throughout the years to have an understanding on what to do, how to work etc.". 
Finding the right balance between the project creation and the team coaching which includes the delivery of theory and practice regarding team management will be a challenge for future undertakings, however the role of the team advisor will remain.

\section{Linking Education and Industry: Creative Industry Day}

The introduction of the industry panel was very well received by students. Of the eighteen digital media design students who gave feedback regarding their perception of the day, seventeen $(95 \%)$ thought it was a good experience and that the feedback from the professionals was helpful. Only one student thought the feedback was not helpful and the day was not a good experience.

The variety offered at the day (panel discussion, presentation, feedback session) was influential for students on many different levels:

- "[IT] was good to hear about the industry during their talks, and also to give a presentation in front of them. I feel that this challenged us more than normal (normally we give presentations to lecturers) as we weren't $100 \%$ sure as to how they would react from an industry perspective."

- To get people that have no emotional attachment to the project and see it like it is, not for its potential or how far a particular group has come along was refreshing for outside feedback as well as the lecturers' feedback so we can make the best possible product."

- "They gave really good advice that was really valuable as they were looking from the outside in and suggested some things we would not have or could not have considered."

- "I liked the insight about the hazards of working in a team. When I heard them I realised that our team has made a lot of the mistakes they pointed out. It would have been extremely helpful if this day was moved to the beginning of the semester."

- "It changed the way that we are going to present our final presentation."

- "It made me realise though that I should stick to my disciplinary area for my chosen career and try to master it."

- "I ended up keeping in contact with one of the professionals with help on advertising and marketing"

It is also worth mentioning that two digital media design students gained part time employment as a result of this event.

\section{Reflections from Industry Professionals}

The feedback from the four industry professionals was positive and very pleasing. All agreed that it is very important to involve industry into the learning environment, hence found the integration of industry and community through the POOL Model framework beneficial. Some feedback from the industry professionals illustrate this point:

"[Industry professionals] know all the different things that are changing. Whereas I guess when you [referring to academics] are not doing it all the time it is hard to know what is going on in the industry. So bringing in those people who are dealing with it every day really helps to give the students a bit more up-to-date knowledge. 
I think it is important to talk to students ... so they are more prepared for [the industry] when they leave university. I think it is important for them to have that engagement with the industry that they want to get into once they leave. The more preparation the better! Less shock!

I think it is really important [to involve industry] because it just gives students a real life person in the real life world to be able to relate to. ... a real life perspective. ... This is something that is very close to what you would be doing in the real world. You need to be prepared for this now so that it helps you enter into the work force.

"I ... think it is very important that ... influence from the outside world comes in [because] academia is not an ivory tower another world of its own. ... I think it is a very good approach and a very valid approach, ...to confront students to the outside world and to make them understand the clocks are slightly ticking differently to the outside."

\section{Conclusion}

The POOL Model framework, trialed in its most advanced version, engaged $3^{\text {rd }}$ year undergraduate design students in collaborative teamwork with students from a range of disciplines including digital imaging, digital sound, digital visual arts, performance, and IT. While much of the collected data is currently awaiting transcription and evaluation, the data collected through online questionnaires and early analysis of interview data obtained from industry and community partners suggests that the subject was extremely successful.

The feedback from students has been overwhelmingly positive to date and learning outcomes have been very pleasing. Indeed the feedback suggests that discipline-specific learning while simultaneously engaging students in multidisciplinary collaboration was facilitated. Multidisciplinary teams of students were able to learn to communicate ideas across disciplines, and to lead, manage and contribute effectively to their teams, thus developing an understanding of professional requirements in adjacent areas. As a result students are better prepared for their future collaborative multidisciplinary work environment in the creative industries.

External input from industry and community into the academic environment becomes critical to close an identified gap between the real world and academic environment. Feedback from industry professionals supports this view and reflection from students further sustain that strengthening links with industry is beneficial.

Research is ongoing, and the results from 2009 will influence the further development of subjects offered within the POOL Model framework. It is crucial to identify more beneficial links to other disciplines, so that the learning and teaching pool can be meaningfully expanded. Facilitating collaborations across a wide variety of disciplines also provides greater flexibility in creating projects that are reflective of industry practice. To further extend the opportunities for students to engage with a broad range of disciplines, future collaborations have already been formalized, for example with journalism department of the School of Arts and Social Sciences, which will be part of the learning and teaching pool in starting 2011. 


\section{References}

Ball, L 2003, Future directions for employability research in the creative industries. Report from the Art, Design and Communication - Learning and Teaching Support Network (ADC-LTSN), viewed on October 18, 2007, http://www.adm.heacademy.ac.uk/resources.

Bley, T 2004, A new graduate programme in design, International Design Network and Institute, Dulles, VA. Retrieved February 12, 2005 from http://new.idsa.org/webmodules/articles/articlefiles/ed_conference02/04.pdf.

Business Week 2007, D-Schools: The global list. Business Week online, viewed on April 4, 2008, http://bwnt.businessweek.com/interactive_reports/talenthunt/index.asp.

Collins, R, Curtis, O, Curtis, S \& Stevenson, L 2007, 'Community Engagement as a Cornerstone enabling learning and teaching and research in the post modern world', The Australasian Journal of University Community Engagement, Vol 2, No 1, Spring 2007.

Design Skills Advisory Panel 2007, High-level skills for higher value. UK Design Industry Skills Development Plan; Design Council, Creative \& Cultural Skills, London, UK, viewed on July 30, 2007, http://www.designcouncil.org.uk/en/Design-Council/3/Publications.

Design Council 2005, The business of design. Report on design business research 2005, viewed on June 22, 2006, http:/www.designcouncil.org.uk/en/Design-Council/3/Publications.

Fleischmann, K 2008a, Facilitating sustainable partnerships between university, industry and the community within a new model for tertiary digital media design education. Proceedings of AUCEA National Conference 2008. Sunshine Coast. Australian Universities Community Engagement Alliance Inc., pp. 110-116.

Fleischmann, K 2008b, Overcoming disciplinary boundaries in undergraduate design education: Preparing digital media design students for collaborative multidisciplinary research practice. Proceedings of ACUADS Conference 2008, Australian Council of University Art and Design Schools.

Fleischmann, K 2009, Managing collaboration: A new learning and teaching model for digital media design in higher education, Conference proceedings of International Conference of Education, Research and Innovation, Madrid, Spain, $16^{\text {th }}-18^{\text {th }}$ November.

Fleischmann, K 2010, The POOL Model: Foregrounding an alternative learning and teaching approach for digital media design in higher education. Art, Design and Communication in Higher Education, Vol 9, No 1, pp. 57 - 73.

Harvey, L, Locke, W \& Morey, A 2002, 'Enhancing employability, recognising diversity - Making links between higher education and the world of work', Report, viewed on September 15, 2007, http://www.universitiesuk.ac.uk/employability.

Kelly, V 2005, 'Towards a Design Community: Collaborative Practice in Design Education', Conference Paper, ACUADS 2005.

Price, A 2005, 'Attitudes to clients or clients with attitude?' Publication of the Conference Papers ACUADS 2005, viewed on April 25, 2008, http://www.acuads.com.au.

Snell, T 2006, 'Building bridges: University art galleries as agents of community engagement', Conference Paper ACUADS 2006, viewed on April 25, 2008, http://www.acuads.com.au/conf2006/art ed.htm

Staples, L 2001, The new design basics. In S. Heller (Ed.), The education of an e-designer, New York: Allworth Press, pp. 6-9.

Szenasy, S 2004, School survey 2004 - Do America's design schools encourage interdisciplinary collaboration? Metropolis, August/September 2004, pp. 88-91.

Triggs, T, 2004, Curricula of collaboration: Educating postgraduate students for the workplace. pp. 64-82, viewed on November 7, 2006 from www.arts.ac.uk/docs/cltad_2002triggs.pdf.

West, H 2007, The Cross-Discipline Design Imperative, Business Week Special Report, October 4, 2007. 
Whyte, J \& Bessant, J 2007, Making the most of UK design excellence: Equipping UK designers to succeed in the global economy. Innovation Studies Centre, Tanaka Business School, Imperial College London, viewed on December 13, 2007, http://www.audidesignfoundation.org.

\section{About the Author}

Prof. Katja Fleischmann

Katja Fleischmann is a digital media design and new media arts educator at the School of Creative Arts at James Cook University, Australia. Her international experience as designer and educator informs her current research interest: Managing the Increasing Complexity of Technology in Design Education. Katja Fleischmann has taught, studied and worked in Miami, New York, London, Bournemouth, Wuerzburg and Berlin. One of her key focal points in her academic work is to establish sustainable relationships between the Creative Arts and the local community and industry. As researcher she publishes frequently on the development and implementation of an alternative learning and teaching model for undergraduate digital media design education. She has received national recognition from the Australian Learning and Teaching Council for this work. 